\title{
Analysis of human papilloma virus type 52 integration status in exfoliated cervical cells
}

\author{
KE ZHANG $^{1 *}$, ZHANJUN LIU $^{1 *}$, JI LI $^{1}$, JUAN LI $^{1}$, JIANGHONG YAN $^{1}$, \\ YUNCHUAN SU ${ }^{1}$, SHUYING LI ${ }^{1 *}$ and JINTAO $\mathrm{LI}^{2 *}$

\begin{abstract}
${ }^{1}$ Hebei Key Laboratory for Chronic Diseases/Tangshan Key Laboratory for Preclinical and Basic Research on Chronic ${ }^{2}$ College of Life Science and Bioengineering, Beijing University of Technology, Beijing 100124, P.R. China
\end{abstract} \\ Diseases, School of Basic Medical Sciences, North China University of Science and Technology, Tangshan, Hebei 063000;
}

Received December 1, 2016; Accepted August 22, 2017

DOI: $10.3892 / e t m .2017 .5279$

\begin{abstract}
To explore the significance of human papilloma virus type 52 (HPV52) infection and its integration in cells within cervical lesions, the expression levels of HPV52 were detected using polymerase chain reaction (PCR). The copy numbers of HPV52 E2, HPV52 E6 and the reference gene $\beta$-actin were determined by quantitative PCR to analyze the association between HPV52 integration and cervical lesions. HPV52 integration was analyzed by the amplification of papillomavirus oncogene transcripts. A total of 13 samples from 468 cases were positive for HPV52. Among the samples, 1 case with an E2/E6 ratio $>1$ was purely episomal, 3 cases with an E2/E6 ratio of 0 were purely integrated, and 9 cases with an E2/E6 ratio of between 0 and 1 were a mixture of integrated and episomal. With the progression of cervical disease, the prevalence of the episomal type decreased gradually, and the prevalence of the integrated (episomal and integrated) forms increased. The pure integration of HPV52 occurred in chromosomes 2, 5 and 8. These results indicate that HPV52 integration into the host genome may be a key factor in cervical lesions. Thus, patients at high risk for cervical lesions may potentially be identified by screening for HPV52 infection and integration.
\end{abstract}

Correspondence to: Dr Shuying Li, Hebei Key Laboratory for Chronic Diseases/Tangshan Key Laboratory for Preclinical and Basic Research on Chronic Diseases, School of Basic Medical Sciences, North China University of Science and Technology, 57 Jianshe South Road, Tangshan, Hebei 063000, P.R. China E-mail: 1sy5001@sina.com

Dr Jintao Li, College of Life Science and Bioengineering, Beijing University of Technology, 100 Pingleyuan, Beijing 100124, P.R. China

E-mail: 511046476@qq.com

*Contributed equally

Key words: human papillomavirus, cervical lesions, infection, integration

\section{Introduction}

Cervical cancer is one of the most commonly occurring cancer types in females worldwide (1-3). Each year, new cases of cervical cancer are detected in $\sim 528,000$ women, and the worldwide fatality toll of cervical cancer is $\sim 275,000$ (3-5). High-risk human papillomavirus (HPV) infection is the primary cause of cervical carcinogenesis (6). More than 200 different HPV genotypes have been identified, there are $>10 \%$ differences in the $\mathrm{L} 1$ nucleotide sequence between the genotypes (7). A minimum of 13 high-risk HPV genotypes (HPV16, 18, 31, 33, 35, 39, 45, 51, 52, 56, 58, 59, and 68) (8) are recognized as the causative agents of cervical cancer and numerous other types of cancer (9). HPV16 and HPV18 are the two most prevalent genotypes in cervical cancer (CC) (10). Although the high prevalence of HPV16/18 in CC is common throughout the world, the distribution of other high-risk HPV types in the remaining fraction of $\mathrm{CC}$ reveals region-specific variations (11). Notably, in East Asian countries (including Japan, South Korea, Taiwan and China) HPV52 infection is more prevalent compared with European, North American and African regions (12-15). The present study has focused on this type of HPV. The HPV E2 protein controls replication, transcription and viral genome partitioning during the viral infectious life cycle (16). The HPV E2 protein is a key transcriptional regulator of the E6 and E7 genes (17). HPV DNA sequences are typically integrated into the host cell genome, and cervical cancer progression is significantly associated with integration of the viral genome (18-20). Integrated and episomal HPV may be confirmed using a polymerase chain reaction (PCR)-based protocol for the amplification of papillomavirus oncogene transcripts (APOT), which was developed by Klaes et al (21). This protocol is based on the hypothesis that HPV transcripts derived from the integrated HPV genome represent suitable molecular markers for a cervical lesion at risk of progression to carcinoma. However, there are limited available data concerning HPV52 status and integration patterns.

The aim of the present study was to assess HPV52 infection and integration into the host cell genome in exfoliated cervical cells. Briefly, cervical cytology specimens were collected and genomic DNA and RNA were extracted from each sample. 
For every specimen HPV DNA was detected using polymerase chain reaction (PCR) amplification with the MY09/11 primers (22), HPV52 was detected using HPV52 type-specific primers. The viral load and integration state were determined for HPV52 positive specimens by quantitative (q)PCR using HPV52 E2, E6 and $\beta$-actin primers, the number of copies of HPV52 was calculated using the formula: (E6 copy/ $\beta$-actin copy) $\mathrm{x} 2$, and the HPV52 integration state was determined by the ratio of E2 to E6 copy number. The integration of HPV in the host chromosome integration site may be accurately located by detecting transcription of the poly (A) tail $(21,23,24)$. cDNA was synthesized by reverse transcription using an RNA template, and a (dT) $)_{17}$-p3 as primer; PCR amplification was conducted using cDNA as a template and p1-HPV52 E7 and p3 as primers; nest PCR was conducted using the product as a template and p2-HPV52 E7 and (dT) $)_{17}$-p3 as primers; the PCR product underwent sequence analysis. The integration sites were determined by sequence alignment of the HPV and human chromosome sequence.

\section{Materials and methods}

Specimen collection. Cervical cytology specimens from 468 female patients were collected from the Affiliated Hospital of North China University of Science and Technology (Tangshan, China) between October 2012 and June 2014. These specimens were collected through a sterile swab scraped in a clockwise rotation three times in the cervix from every patient, the cervical exfoliation cells were subsequently washed down from the swab using physiological saline solution and collected. The age of the patients ranged from 26-60 years, and the mean age was $41.5 \pm 5$ years. The patients had no medical history of cervical diseases prior to this diagnosis and were not menstruating or pregnant. The inclusion criteria for all cases was a conventional cervical cytology diagnosis; exclusion criteria were a diagnosis and treatment for cervical intraepithelial neoplasia, cervical cancer and hysterectomy prior to the study. The present study was approved by the Ethics Committee of North China University of Science and Technology, and every specimen donor provided informed consent. These specimens were stored at $-80^{\circ} \mathrm{C}$.

Reagents. The Ex Taq Polymerase kit and pMD-18T vector kit were provided by Takara Biotechnology Co., Ltd., Dalian, China. EvaGreen was provided by Biotium, Inc., Freemont, CA, USA. AmpliTaq Gold DNA Polymerase kit was provided by Applied Biosystems; Thermo Fisher Scientific, Inc., Waltham, MA, USA. The RNeasy Mini kit was provided by Qiagen GmbH, Hilden, Germany. Goldview I nuclear staining dye and M-MLV Reverse Transcriptase kit were provided by BioTeke Corporation, Beijing, China.

Media. Dulbecco's modified Eagle medium (DMEM) with antibiotics (100 U/ml penicillin-streptomycin), PBS, fetal bovine serum, trypsin, lysogeny broth and other media used in the present study were provided by BioTeke Corporation.

Plasmid and cell DNA. The plasmid including the complete HPV52 genome, the plasmid encorporating part of the human $\beta$-actin gene, 293 and HeLa cell DNA, and E. coli DH5 $\alpha$ competent cells, were obtained from the National Institute for Viral Disease Control and Prevention, Chinese Center for Disease Control and Prevention (Beijing, China).

Cell culture conditions. The HeLa and 293 cells (National Institute for Viral Disease Control and Prevention, Chinese Center for Disease Control and Prevention) were cultivated using $10 \mathrm{ml}$ media (DMEM with $100 \mathrm{U} / \mathrm{ml}$ penicillin-streptomycin and $10 \%$ fetal bovine serum) in a $10 \mathrm{~cm}$ diameter petri dish and maintained at $37^{\circ} \mathrm{C}$ in a humidified atmosphere with $5 \% \mathrm{CO}_{2}$. The fresh cell media was changed every 2-3 days.

Pathological cytology. The cervical cytology specimens were diagnosed by pathological cytology according to the 2001 Bethesda system (TBS) $(25,26)$. According to the TBS, the cytological diagnosis of abnormal cervical squamous cells is divided into the following categories: Atypical squamous epithelial cells (ASC) of undetermined significance; ASC-cannot exclude high-grade squamous epithelial lesion (HSIL); low-grade squamous intraepithelial lesion (LSIL); and HSIL. Sample smear preparation and staining were performed using BD PrepStain ${ }^{\mathrm{TM}}$ Slide Processor (BD Biosciences, San Jose, CA, USA) according to the manufacturer's protocol, and the results were observed using an optical microscope.

Primer design and synthesis. The primers used for HPV52 E2 and E6 were designed according to the HPV52 gene sequence in GenBank (X74481.1; http://www.ncbi.nlm.nih .gov/nuccore/X74481) and were synthesized with the $\beta$-actin primer by Sangon Biotech Shanghai Co., Ltd. (Shanghai, China). The primer sequences for HPV52 E2, HPV52 E6 and $\beta$-actin are presented in Table I.

Detection of specimen quality. Genomic DNA was extracted from each exfoliated cervical cell sample using the phenol-chloroform method $(27,28)$. The quality of the sample DNA was determined by PCR amplification which was conducted using a Takara Ex Taq kit in a $20 \mu \mathrm{l}$ reaction mixture [containing $1 \mathrm{X}$ Ex Taq Buffer $\left(\mathrm{MgCl}_{2}\right.$ free), $2.5 \mathrm{mM} \mathrm{MgCl}, 0.2 \mathrm{mM}$ dNTPs, 1 unit Ex Taq DNA polymerase, 5 pmol $\beta$-actin primers, $40 \mathrm{ng}$ sample DNA template], the 293 cell DNA served as a positive control and sterile water served as a negative control. The thermocycling profile used was as follows: $95^{\circ} \mathrm{C}$ for $5 \mathrm{~min}$; followed by 31 cycles of $95^{\circ} \mathrm{C}$ for $30 \mathrm{sec}, 55^{\circ} \mathrm{C}$ for $30 \mathrm{sec}$ and $72^{\circ} \mathrm{C}$ for $30 \mathrm{sec}$; followed by a final extension at $72^{\circ} \mathrm{C}$ for $5 \mathrm{~min}$; and storage at $4^{\circ} \mathrm{C}$.

Detection of HPV DNA. HPV DNA was detected in each exfoliated cervical cell sample using PCR as described above with the MY09/11 primers (MY09: 5'-CGTCCMARRGGAWAC TGATC-3'; MY11: 5'-GCMCAGGGWCATAAYAATGG-3'; (amplicon size, $450 \mathrm{bp}$ ) for the HPV L1 gene as described previously (22). The PCR products were resolved on a $1 \%$ agarose gel and visualized using Goldview I nuclear staining dye. The MY09/11 primers are able to detect $>20$ HPV types, including HPV52. In the present experiment, HPV infection-free 293 cell DNA was used as a negative control, and HeLa cell DNA and HPV52 plasmid DNA were used as positive controls. HeLa cell DNA was used as a HPV52 type-specific control and HPV52 plasmid DNA was used as a positive control to 
Table I. Primers used in the present study.

\begin{tabular}{|c|c|c|c|}
\hline Primer & Sequence $\left(5^{\prime}-3^{\prime}\right)$ & Position & Amplicon size (bp) \\
\hline \multicolumn{4}{|c|}{ HPV52 E2 primers } \\
\hline HPV52 E2-1 & GGAAAACGATGGAGTCGATAC & $2735-2755$ & 176 \\
\hline HPV52 E2-2 & GTGGCCTATATGAGTTATTC & 2891-2910 & \\
\hline HPV52 E2-3 & CGATGCAAAGCAATATTGTG & $3261-3280$ & 235 \\
\hline HPV52 E2-4 & GTACTTGGTGTTTCTGGAGTC & $3475-3395$ & \\
\hline HPV52 E2-5 & GCACCTATAATACACCTAAAAGG & $3604-3626$ & 245 \\
\hline HPV52 E2-6 & CACAATGACATGACACCTTG & $3829-3848$ & \\
\hline \multicolumn{4}{|c|}{ HPV52 E6 primers } \\
\hline HPV52 E6-1 & GTTTGAGGATCCAGCAACAC & $104-123$ & 369 \\
\hline HPV52 E6-2 & CGCTTGTTTGCATTAACATG & $453-472$ & \\
\hline \multicolumn{4}{|l|}{$\beta$-actin primers } \\
\hline Forward & CACCCACACTGTGCCCATCT & $550-560$ & 289 \\
\hline Reverse & GAACCGCTCATTGCCAATGG & $819-838$ & \\
\hline
\end{tabular}

HPV, human papilloma virus.

detect HPV52 E6 using HPV52 type-specific primers. PCR was conducted in a $20-\mu 1$ reaction mixture containing $1 \mathrm{X}$ Ex Taq Buffer ( $\mathrm{MgCl}_{2}$-free), $2.5 \mathrm{mM} \mathrm{MgCl}{ }_{2}, 0.2 \mathrm{mM}$ dNTPs, 1 unit Ex Taq DNA polymerase, 5 pmol of each primer from the primer pair described above (MY09/MY11 or HPV52 E6 primers) and $40 \mathrm{ng}$ sample DNA or control DNA. The thermocycling profile used was as follows: $95^{\circ} \mathrm{C}$ for $5 \mathrm{~min}$; followed by 31 cycles of $95^{\circ} \mathrm{C}$ for $30 \mathrm{sec}, 55^{\circ} \mathrm{C}$ for $30 \mathrm{sec}$ and $72^{\circ} \mathrm{C}$ for $30 \mathrm{sec}$; followed by a final extension at $72^{\circ} \mathrm{C}$ for $5 \mathrm{~min}$; and a holding temperature of $4^{\circ} \mathrm{C}$. The PCR products were resolved on a $1.0 \%$ agarose gel and observed with a UV transilluminator.

qPCR analysis. The viral load and integration state were determined using qPCR with HPV52 E2/E6/ $\beta$-actin primers. Briefly, the number of copies of HPV52 was calculated using the formula: (E6 copy/ $\beta$-actin copy) x 2 , and the HPV52 integration state was determined by the ratio of E2 to E6 copy number. The reactions were performed in a $25-\mu 1$ reaction mixture and standard curves were generated with quantified DNA standards (a 10-fold dilution series of full length HPV52 and $\beta$-actin plasmids). The PCR mixtures consisted of $1 \mathrm{X}$ AmpliTaq gold buffer $\left(\mathrm{MgCl}_{2}\right.$-free), $2.5 \mathrm{mmol} / \mathrm{l}$ $\mathrm{MgCl}_{2}, 0.2 \mathrm{mmol} / 1 \mathrm{dNTPs}, 2 \mathrm{pmol} / 1$ primers, 20X EvaGreen (1.25 $\mu \mathrm{l}$ ), $0.25 \mu \mathrm{l}$ RX (stabilizer), $2 \mu \mathrm{l}$ AmpliTaq Gold DNA polymerase, $0.4 \mu \mathrm{l}$ DNA template $(80 \mathrm{ng} / \mu \mathrm{l})$ and double distilled water to a final volume of $25 \mu \mathrm{l}$. The initial denaturation was performed at $95^{\circ} \mathrm{C}$ for $5 \mathrm{~min}$; followed by 5 cycles of $95^{\circ} \mathrm{C}$ for $1 \mathrm{~min}, 55^{\circ} \mathrm{C}$ for $1 \mathrm{~min}$ and $72^{\circ} \mathrm{C}$ for $1 \mathrm{~min}$; followed by 35 cycles at $95^{\circ} \mathrm{C}$ for $30 \mathrm{sec}, 55^{\circ} \mathrm{C}$ for $50 \mathrm{sec}$ and $72^{\circ} \mathrm{C}$ for $50 \mathrm{sec}$; and a final extension at $72^{\circ} \mathrm{C}$ for $5 \mathrm{~min}$. The threshold cycle $(\mathrm{Cq})(29,30)$ was determined by the CFX96 Touch Real-time PCR system (Bio-Rad Laboratories, Inc., Hercules, CA, USA), with the baseline set automatically to standard deviations above the background fluorescence generated in the first five cycles. For each specimen, identical amounts of DNA were analyzed for E6 and E2 and compared with expression of the internal reference gene $\beta$-actin. The specificity of each amplification was confirmed by checking the dissociation curve against the expected melting temperature of the amplification product.

Reverse transcription (RT). RNA was extracted from the patient samples that were identified to have integrated HPV52 using the RNeasy Mini kit. RT was performed using Oligo (dT) $)_{17}$-p3 (primer: 5'-GACTCGAGTCGACATCGATTTTTT TTTTTTTTTTT) to produce double-stranded DNA, which was subsequently amplified using PCR. The components of the RT reaction were as follows: RNase-free $\mathrm{H}_{2} \mathrm{O}(9.2 \mu \mathrm{l}), 5 \mathrm{X}$ first-strand buffer (BioTeke Corporation; $4 \mu \mathrm{l}$ ), $0.2 \mathrm{mmol} / \mathrm{l}$ dNTPs $(1 \mu \mathrm{l}), 40$ units RNase inhibitor $(1 \mu \mathrm{l}), 10 \mathrm{pmol}(\mathrm{dT})_{17}-\mathrm{p} 3$ (oligonucleotide primer, GACTCGAGTCGACATCGATTT TTTTTTTTTTTTTT-3'; $1 \mu \mathrm{l}$ ), 200 units SuperScript reverse transcriptase (BioTeke Corporation; $1 \mu \mathrm{l}$ ), and total RNA $(0.5-1 \mu \mathrm{g})$ in a total volume of $20 \mu \mathrm{l}$. RNA was reverse transcribed by heating at $42^{\circ} \mathrm{C}$ for $50 \mathrm{~min}$, and the reaction was terminated by heating at $70^{\circ} \mathrm{C}$ for $15 \mathrm{~min}$. The cDNA samples were stored at $4^{\circ} \mathrm{C}$.

To confirm that HPV52 E7 mRNA was detectable in all of the samples and to ensure that the isolated mRNA was of sufficient integrity for PCR amplification, mRNA corresponding to the human reference gene GAPDH was analyzed by RT-PCR. The RT reactions were performed using a Power M-MLV Reverse Transcriptase kit (BioTeke Corporation) according to the manufacturer's protocol and the cDNA was stored at $4^{\circ} \mathrm{C}$. The PCR was conducted using a Takara Ex Taq Polymerase kit in a $20 \mu \mathrm{l}$ reaction mixture containing $1 \mathrm{X}$ Ex buffer $\left(\mathrm{MgCl}_{2}\right.$-free), $2.5 \mathrm{mM} \mathrm{MgCl}{ }_{2}, 0.2 \mathrm{mM} \mathrm{dNTPs,} 1$ unit Ex Taq DNA polymerase, 5 pmol each GAPDH primer (forward, 5'-CATCACCATCTTCCAGGA-3' and reverse, 5'-GTCTAC CACCCTATTGCA-3') and $2 \mu \mathrm{l}$ cDNA as a template. The thermocycling profile used was as follows: $95^{\circ} \mathrm{C}$ for $5 \mathrm{~min}$; followed by 31 cycles of $95^{\circ} \mathrm{C}$ for $30 \mathrm{sec}, 52^{\circ} \mathrm{C}$ for $30 \mathrm{sec}$ and $72^{\circ} \mathrm{C}$ for $30 \mathrm{sec}$; followed by a final extension at $72^{\circ} \mathrm{C}$ for $5 \mathrm{~min}$; and storage at $4^{\circ} \mathrm{C}$. 
Detection of viral-cell fusion transcripts using nested PCR. The generation of viral-cellular fusion transcripts encompasses the E6-E7-E1 sequences at their 5'-ends and cellular sequences at their 3 '-ends. APOT analysis used an oligo(dT)17-primer coupled to a linker sequence (dT)17-p3, the RT of all of the mRNAs was initiated by binding to their poly(A) tail, and integrate-derived HPV oncogene transcripts were amplified by nested PCR reactions as described previously $(21,23,24)$. The cDNA was synthesized by RT using RNA as a template and (dT)17-p3 as a primer. Nested PCR amplification was then performed. The first PCR reactions were performed using cDNA as a template, and p1-HPV52 E7 and p3 as primers. The second PCR reactions were conducted using first PCR products as template, and p2-HPV52 E7 and (dT)17-p3 as primers. First PCR reactions were conducted with $10 \mathrm{pmol} / 1$ primers (forward, p1-HPV52 E7, 5'-CTACGGCTATGCATTCAT AGC-3'; and reverse, p3, 5'-GACTCGAGTCGACATCG-3'), 1X Ex buffer, $2.5 \mathrm{mmol} / 1 \mathrm{MgCl}_{2}, 0.2 \mathrm{mmol} / \mathrm{l}$ dNTPs, 1 unit Ex Taq DNA polymerase, and $2 \mu \mathrm{l}$ cDNA in a total volume of $25 \mu \mathrm{l}$; following thermocycling conditions: $95^{\circ} \mathrm{C}$ for $5 \mathrm{~min}$; followed by 30 cycles of denaturation at $95^{\circ} \mathrm{C}$ for $1 \mathrm{~min}$, annealing at $56^{\circ} \mathrm{C}$ for $1 \mathrm{~min}$ and elongation at $72^{\circ} \mathrm{C}$ for $3 \mathrm{~min}$; followed by a final extension at $72^{\circ} \mathrm{C}$ for $5 \mathrm{~min}$. Then, second PCR was performed using the first PCR product $(5 \mu \mathrm{l})$ as a template, and using the p2-HPV52 E7 forward primer (5'-CGTACTCTA CAGCAAATGCTGTTG-3') and the (dT) $)_{17}-\mathrm{p} 3$ reverse primer, with the exception that annealing was performed at $67^{\circ} \mathrm{C}$. The positions of the two primers were 751-771 for p1-HPV52 and 787-810 for p2-HPV52. To control for false-positives, a negative control (293 cell DNA template) was included in each set of amplifications. Electrophoresis was performed using a 1.2\% agarose gel with Goldview I nuclear staining dye.

Cloning and sequence analysis. To further confirm specific HPV52 oncogene transcription in all of the samples, the final nested PCR products were cloned into a pMD-18T vector according to a previous study (31), except the temperature of the target segment ligation to the pMD-18T vector was changed to room temperature for $1 \mathrm{~h}$. Then Beijing Rui Bo Xing ke Biological Technology (Beijing, China) was commisioned to sequence the products. The results were analyzed using the National Center for Biotechnology Information BLAST (blast.ncbi.nlm.nih.gov/Blast.cgi?PROGRAM=blastn\&PAGE _TYPE=BlastSearch\&LINK_LOC=blasthome), and HPV52 integration sites in human chromosomes were determined for every integration specimen.

\section{Results}

Determination of specimen DNA quality. The 289-bp $\beta$-actin product size was confirmed by agarose gel electrophoresis, and PCR amplification of $\beta$-actin in the DNA specimens and the positive control was observed to be similar (Fig. 1). The results suggest that all of the DNA samples were of satisfactory quality for subsequent experiments.

Detection of HPVDNA in the samples. In total, $52 \mathrm{HPV}$-positive samples were identified from among the 468 samples by PCR using the MY09/11 general primer set, which generated a 450-bp product (Fig. 2A). Among them, 13 cases were found to

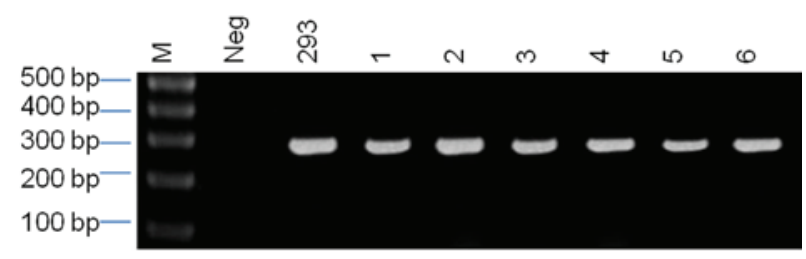

Figure 1. Detection of $\beta$-actin in exfoliated cervical cell DNA samples. M, 100 bp marker; Neg, negative control; 293, 293 cell DNA template as a positive control for $\beta$-actin; lanes 1-6, exfoliated cervical cell DNA samples.

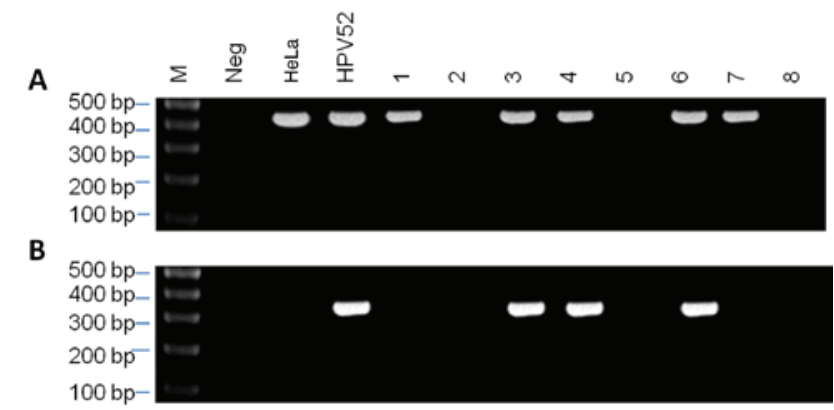

Figure 2. Detection of HPV. HPV in DNA samples from exfoliated cervical cells detected using primer pairs for (A) MY09/11 and (B) HPV52 E6. M, 100 bp marker; Neg, negative control; HeLa, positive and specific control for HPV detection; HPV52, positive control; lanes 1-8, exfoliated cervical cell DNA samples. HPV, human papilloma virus.

be HPV52-positive using the HPV52 E6 type-specific primer set, which generated a 369-bp product (Fig. 2B).

Association between cervical lesions and HPV52 infection. The 13 HPV52-positive samples were subjected to cytological diagnosis, which indicated that these 13 samples included 1 case of ASC (Fig. 3A), 5 cases of LSIL (Fig. 3B) and 7 cases of HSIL (Fig. 3C).

Analysis of HPV52 infection and viral load. The standard curve and copy number of $\beta$-actin, E2 and E6 for every sample were automatically generated and determined by the qPCR instrumentation based on six 10 -fold dilutions of $\beta$-actin, E2 and E6 standard plasmids. The HPV52 viral load of each sample was calculated (Table II). No clear association of lesion pathology with viral load was observed.

The HPV52 integration status was determined based on the E2/E6 ratio. Among the 13 HPV52-positive samples, 1 case was episomal, and the E2 gene was not destroyed. A total of 3 cases were fully integrated, with E2/E6=0. The remaining 9 cases were a mix of integrated and episomal, with an E2/E6 ratio $>0$ and $<1$. The results are presented in Table II. As the pathology of the lesions advanced from ACS to LSIL and HSIL, the proportion of episomal cases decreased and that of integrated (episomal + integrated) cases increased. These results indicate that the pathology of the cervical lesions is associated with HPV52 infection and viral DNA integration into the host genome.

Location of HPV52 integration in the host chromosome. RNA was extracted from the HPV52-integrated samples. 
Table II. Distribution of viral load and integration state of HPV52.

HPV52 integration state, $\mathrm{n}(\%)$

\begin{tabular}{|c|c|c|c|c|c|}
\hline \multirow[b]{2}{*}{ Cytodiagnosis } & \multirow{2}{*}{$\begin{array}{c}\text { Viral load } \\
\text { (copy no./cell) }\end{array}$} & \multirow[b]{2}{*}{ No. of cases } & \\
\hline & & & Episomal & Mixed $^{a}$ & Integrated \\
\hline ASC & 23.26 & 1 & $1(100.0)$ & 0 & 0 \\
\hline LSIL & $9.88-189.25$ & 5 & 0 & $4(80.0)$ & $1(20.0)$ \\
\hline HSIL & $19.52-98.52$ & 7 & 0 & $5(71.4)$ & $2(28.6)$ \\
\hline Total & $9.88-189.25$ & 13 & $1(7.7)$ & $9(69.2)$ & $3(23.1)$ \\
\hline
\end{tabular}

${ }^{a}$ Mixture of episomal and integrated virus. HPV, human papilloma virus; ASC, atypical squamous epithelial cells; LSIL, low-grade squamous intraepithelial lesion; HSIL, high-grade squamous intraepithelial lesion.

A product of $\sim 600 \mathrm{bp}$ was generated according to nested PCR using the E7-specific primers with the template cDNA obtained by RT with oligo (dT) $)_{17}$-p3. In 3 samples, the HPV52 integration site was in human chromosome 2,5 or 8 ; this was determined by sequencing the $\sim 600$ bp product and cloning it into the pMD-18 vector. The sequencing results indicated that the HPV52 E7 PCR product that was amplified using the p2-HPV52 primer was part of the HPV52 E7-E1 sequence (Fig. 4). Another section of the amplified sequence was similar to human chromosome 2 (Fig. 5A), 5 (Fig. 5B) or 8 (Fig. 5C).

\section{Discussion}

Persistent high-risk HPV infection, with HPV types including HPV16, 18 and 31, has been identified as the major causative agent of cervical cancer (32). HPV52 infection is an important factor for cervical, anal and oropharyngeal carcinoma (33-36). Viral load is recommended as a precancer biomarker, but this has been indicated only for HPV16 infection $(37,38)$. qPCR is regarded as the standard method for viral load quantification (39). Although viral load has been recommended as a precancer biomarker for HPV16 infection (37-39), there is no consistent evidence that viral load is a useful marker of prevalent disease or disease progression (40-42). In the present study, the results revealed that viral load did not have a clear association with cervical lesion pathology. Multiple E1-L1/E6E7 (including E1/E6E7 and L1/E6E7) ratio analysis has been demonstrated to be more sensitive than E2/E6E7 ratio analysis in the detection of HPV integration status, and may be used to select candidates for cervical biopsy and reduce the incidence of cervical cancer (43).

The present study identified 13 HPV52-positive patients by the analysis of 468 exfoliated cervical cell samples. Among them, 1 was purely episomal, 3 were purely integrated, and 9 were mixed (episomal and integrated). The results of 3 integrated HPV52 samples indicated that the integration of high-risk HPV may have an important role in cervical cancer. Furthermore, viral integration may occur in the E6 and E7 genes or downstream in the E1 or E2 area, causing gene inactivation $(18,44,45)$. Integration of the viral genome is typically caused by an HPV E2 open reading frame that is broken or missing; in such cases, certain areas of the DNA fragment are lost, and the E7 or E6 gene is integrated into the host cell,
A

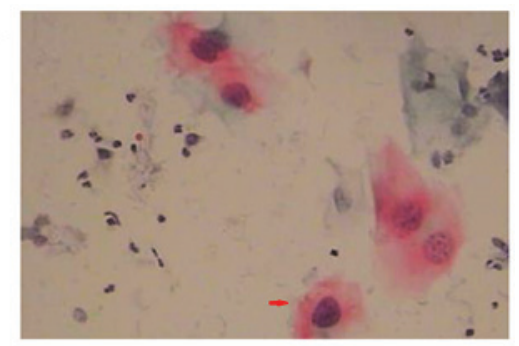

B

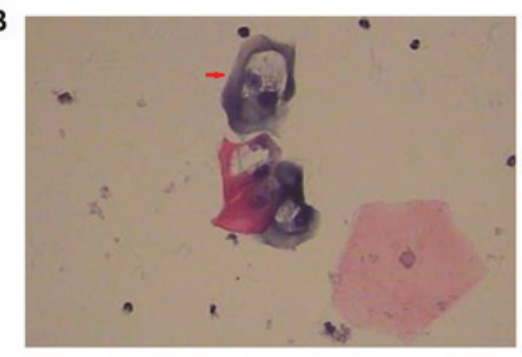

C

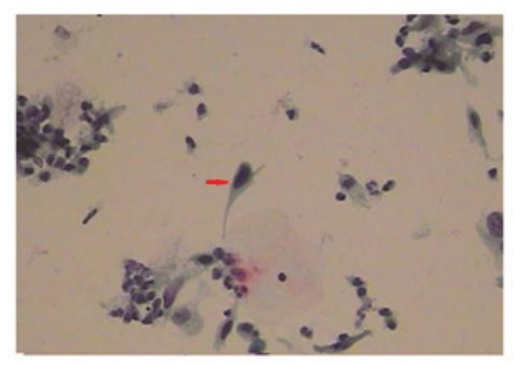

Figure 3. Cytological diagnosis of cervical lesions. (A) Atypical squamous cells, (B) low-grade squamous intraepithelial lesions and (C) high-grade squamous epithelial lesions. (A) The arrowhead indicates the cell volume increased, the cytoplasm was rich, the nucleus was slightly enlarged and nuclear polarity was lacking in the atypical squamous cells. (B) The arrowhead indicates koilocyte was visible near the edge and in the middle of the field of view, with an atypical concave nuclear space, an irregular nuclear membrane, a visible dual-core, a free halo around the nucleus and a stiff surrounding halo, with an iron wire mesh-like shape. (C) The arrowhead indicates the cell was alone with a larger nucleus, the cytoplasm exhibited keratosis and the cytoplasmic area was decreased. Magnification, x400.

which promotes and maintains the integration of the viral genome and the interaction with host genes (46).

Cytological analysis of the 13 HPV18-positive specimens according to the TBS indicated that there was 1 case of ASC, 5 cases of LSIL and 7 cases of HSIL. As the lesion stage advanced from ASC to LSIL and HSIL, the proportion of episomal samples decreased, and that of integrated samples 


\begin{tabular}{|c|c|c|c|c|}
\hline \multirow[t]{4}{*}{ A } & Query & 93 & $\begin{array}{l}\text { GCTGTTGGGCACATTACAAGT TGTGTGCCCCGGCTGTGCACGGCTATAAACAACCCTGCA } \\
\text { | | | | | | | | | | | | | | | | | | | | | | | | | | | | | | | | | | | | | | | | | | | | | | | | | | | | | } \\
\text { GCTGTTGGGCACATTACAAGT TGTGTGCCCCGGCTGTGCACGGCTATAAACAACCCTGCA }\end{array}$ & 152 \\
\hline & Sb jet & 795 & GCTGTTGGGCACATTACAAGTTGTGTGCCCCGGCTGTGCACGGCTATAAACAACCCTGCA & 854 \\
\hline & Query & 153 & 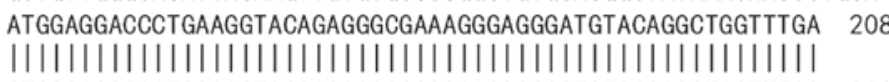 & \\
\hline & Sb jct & 855 & ATGGAGGACCCTGAAGGTACAGAGGGCGAAAGGGAGGGATGTACAGGCTGGTTTGA 910 & \\
\hline B & Query & 92 & 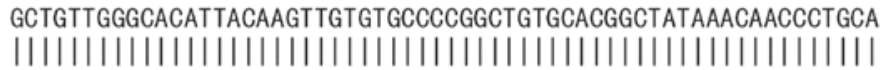 & 151 \\
\hline & Sb jct & 804 & GCTGTTGGGCACATTACAAGTTGTGTGCCCCGGCTGTGCACGGCTATAAACAACCCTGCA & 863 \\
\hline & Query & 152 & $\begin{array}{l}\text { ATGGAGGACCCTGAAGGTACAGAGGGCGAAAGGGAGGGATGTACAGGCTGGTTTGAAGTA } \\
\|\|\|\|\|\|\|\|\|\|\|\|\|\|\|\|\|\|\|\|\|\|\|\|\|\|\|\|\|\|\|\|\|\|\|\|\end{array}$ & 211 \\
\hline & Sb jct & 864 & ATGGAGGACCCTGAAGGTACAGAGGGCGAAAGGGAGGGATGTACAGGCTGGTTTGAAGTA & 923 \\
\hline C & Query & 96 & 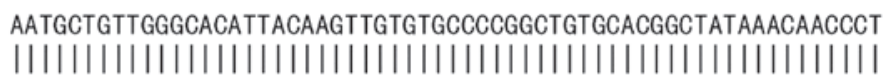 & 55 \\
\hline & Sb jet & 792 & AATGCTGTTGGGCACATTACAAGTTGTGTGCCCCGGCTGTGCACGGCTATAAACAACCCT & 51 \\
\hline & Query & 156 & 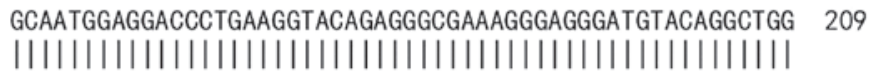 & \\
\hline & Sbjet & 852 & GCAATGGAGGACCCTGAAGGTACAGAGGGCGAAAGGGAGGGATGTACAGGCTGG 905 & \\
\hline
\end{tabular}

Figure 4. Alignment of the sequencing results with HPV52. (A-C) Alignment of the sequencing results of three exfoliated cervical cell specimens with HPV52. Query, sequencing results for the three exfoliated cervical cell specimens following polymerase chain reaction amplification with p2-52 E7-specific primers; Sbjct, part of the HPV 52E7-E1 sequence in GenBank (X74481). HPV, human papilloma virus.

\begin{tabular}{|c|c|c|c|}
\hline Query & 251 & $\begin{array}{l}\text { CCGGGAGCGGGAGGCCCGGGAGAGCTCCGCGGGTCCCCGCGCCCAGTCCCCAGCCGCGCC } \\
\|\|\|\|\|\|\|\|\|\|\|\|\|\|\|\|\|\|\|\|\|\|\|\|\|\|\|\|\|\|\|\|\|\|\|\| \| ~\end{array}$ & 310 \\
\hline Sb jet & 219571380 & CCGGGAGCGGGAGGCCCGGGAGAGCTCCGCGGGTCCCCGCGCCCAGTCCCCAGCCGCGCC & 2195713: \\
\hline Query & 311 & $\begin{array}{l}\text { CCGACCCCGCCGCCCCGGGCCTCGGCTCGCCCTCCGCACCCCCCCCTGCCCCCCCACCGT } \\
|||||||||||||||||||||||||||||||||||||||||||||||||||||||||||||||||| \mid\end{array}$ & 370 \\
\hline Sb jet & 219571320 & CCGACCCCGCCGCCCCGGGCCTCGGCTCGCCCTCCGCACCCCCCCCTGCCCCCCCACCGT & 219571261 \\
\hline Query & 371 & 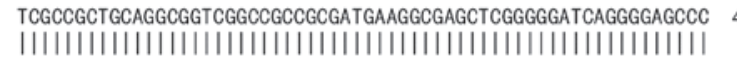 & 430 \\
\hline Sb jet & 219571260 & TCGCCGCTGCAGGCGGTCGGCCGCCGCGATGAAGGCGAGCTCGGGGATCAGGGGAGCCC & 219571201 \\
\hline Query & 431 & 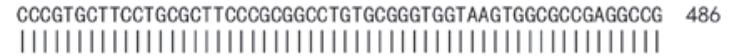 & \\
\hline Sb jet & 219571200 & CCCGTGCTTCCTGCGCTTCCCGCGGCCTGTGGGGGTGGTAAGTGGCGCCGAGGCCG 21957 & 571137 \\
\hline Query & 261 & 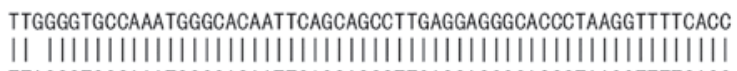 & 320 \\
\hline Sb jct & 112620 & TTAGGGTGCCAAATGGGCACAATTCAGCAGCCTTGAGGAGGGCACCCTAAGGTTTTCACC & 112679 \\
\hline Query & 321 & 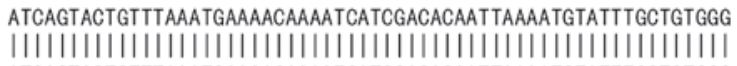 & 380 \\
\hline Sb jct & 112680 & ATCAGTACTGTTTAAATGAAAACAAAATCATCGACACAATTAAAATGTATTTGCTGTGGG & 112739 \\
\hline Query & 381 & 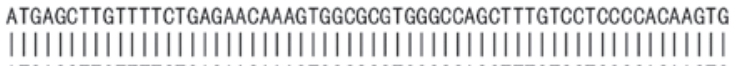 & 440 \\
\hline Sb jct & 112740 & ATGAGCTTGTTTTCTGAGAACAAAGTGGCGCGTGGGCCAGCTTTGTCCTCCCCACAAGTG & 112799 \\
\hline Query & 441 & $\begin{array}{l}\text { GTTGTCCCCTCCTCCCTGTACAAACCCAGGAGAGCCGGGAGGAGCAGCTC } 490 \\
\|\|\|\|\|\|\|\|\|\|\|\|\|\|\|\|\|\|\|\|\|\|\|\|\|\|\|\|\|\| \|\end{array}$ & \\
\hline Sb jet & 112800 & GTTGTCCCCTCCTCCCTGTACAAACCCAGGAGAGCCGGGAGGAGCAGCTC 112849 & \\
\hline Query & 245 & 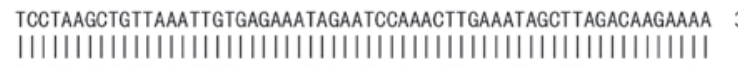 & 304 \\
\hline Sb jct & 146093652 & TCCTAAGCTGTTAAATTGTGAGAAATAGAATCCAAACTTGAAATAGCTTAGACAAGAAAA & 146093711 \\
\hline Query & 305 & $\begin{array}{l}\text { GAGAAATTATTGGGTGGAGAAATCCAAGGAAAAGGTTGTGGAAGGAGCAAGAGGTGGGAG } \\
||||||||||||||||||||||||||||||||||||||||||||||||||||||||\end{array}$ & 364 \\
\hline Sb jct & 146093712 & GAGAAATTATTGGGTGGAGAAATCCAAGGAAAAGGTTGTGCAACGAGCAAGAGGTGGCAG & 146093771 \\
\hline Query & 365 & 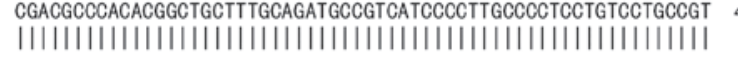 & 424 \\
\hline Sb jct & 146093772 & CGACGCCCACACGGCTGCTTTGCAGATGCCGTCATCCCCTTGCCCCTCCTGTCCTGCCGT & 146093831 \\
\hline Query & 425 & $\begin{array}{l}\text { TAGTCTCCTCTCTGAACTCCACCACCGCCACAGGCAGCCACTGCGGTGCTC } 475 \\
||||||||||||||||||||||||||||||||||||||||||||||||\end{array}$ & \\
\hline Sb jct & 146093832 & TAGTCTCCTCTCTGAACTCCACCACCGCCACAGGCAGCCACTGCGGTGCTC 146 & \\
\hline
\end{tabular}

Figure 5. Alignment of the sequencing results with human chromosomes. The sequencing results for the three exfoliated cervical cell specimens were aligned with human chromosome (A) 2, (B) 5 and (C) 8. Query, sequencing results for the three exfoliated cervical cell specimens following polymerase chain reaction amplification with p2-52 E7-specific primers; Sbjct, part of the human chromosome sequence.

increased for the HPV52-infected patients. The results indicate that pathological changes are associated with integration status, and the 3 HPV52-positive samples integrated into human chromosome 2,5 or 8 . This is consistent with previous results, which have suggested that integration of the viral genome increases the severity of the disease, at least as indicated by biomarker studies of HPV16-infected cervical lesions and precancerous lesions $(38,32,47)$. Therefore, a persistent 
infection following integration of the viral genome into human host cell chromosomes may be key for cell transformation and cancer development.

HPV52 integration into the host genome may be a key factor in cervical lesions, therefore, patients at high risk for cervical lesions may potentially be identified by screening for HPV52 infection and integration.

\section{Acknowledgements}

The present study was supported by the project of Science and Technology for Overseas Scholars in Hebei Province (grant no. CY201620), the Project of Hebei Education Department (grant no. ZD2016003), the Project of North China University Science and Technology (grant no. SP201506) and Beijing Natural Science Foundation (grant no. 5162003).

\section{References}

1. Oh JK and Weiderpass E: Infection and cancer: Global distribution and burden of diseases. Ann Glob Health 80: 384-392, 2014.

2. Arbyn M, Castellsagué X, de Sanjosé S, Bruni L, Saraiya M, Bray $\mathrm{F}$ and Ferlay J: Worldwide burden of cervical cancer in 2008. Ann Oncol 22: 2675-2686, 2011.

3. Vaccarella S, Laversanne M, Ferlay J and Bray F: Cervical cancer in Africa, Latin America and the Caribbean and Asia: Regional inequalities and changing trends. Int J Cancer, Jul 22, 2017 (Epub ahead of print).

4. Nayir T, Okyay RA, Nazlican E, Yesilyurt H, Akbaba M, Ilhan B and Kemik A: Cervical cancer screening in an early diagnosis and screening center in mersin, Turkey. Asian Pac J Cancer Prev 16: 6909-6912, 2015.

5. Torre LA, Bray F, Siegel RL, Ferlay J, Lortet-Tieulent J and Jemal A: Global cancer statistics, 2012. CA Cancer J Clin 65: $87-108,2015$

6. zur Hansen H: Papillomaviruses and cancer: From basic studies to clinical application. Nat Rev Cancer 2: 342-350, 2002.

7. Bzhalava D, Eklund C and Dillner J: International standardization and classification of human papillomavirus types. Virology 476: 341-344, 2015.

8. Arbyn M, Tommasino M, Depuydt C and Dillner J: Are 20 human papillomavirus types causing cervical cancer? J Pathol 234: 431-435, 2014

9. Doorbar J, Egawa N, Griffin H, Kranjec C and Murakami I: Human papillomavirus molecular biology and disease association. Rev Med Virol 25 (Suppl 1): S2-S23, 2015.

10. de Sanjose S, Quint WG, Alemany L, Geraets DT, Klaustermeier JE, Lloveras B, Tous S, Felix A, Bravo LE, Shin HR, et al: Human papillomavirus genotype attribution in invasive cervical cancer: A retrospective cross-sectional worldwide study. Lancet Oncol 11: 1048-1056, 2010.

11. Smith JS, Lindsay L, Hoots B, Keys J, Franceschi S, Winer R and Clifford GM: Human papillomavirus type distribution in invasive cervical cancer and high-grade cervical lesions: A meta-analysis update. Int J Cancer 121: 621-632, 2007.

12. Onuki M, Matsumoto K, Satoh T, Oki A, Okada S, Minaguchi T, Ochi H, Nakao S, Someya K, Yamada N, et al: Human papillomavirus infections among Japanese women: Age-related prevalence and type-specific risk for cervical cancer. Cancer Sci 100: 1312-1316, 2009.

13. Li N, Franceschi S, Howell-Jones R, Snijders PJ and Clifford GM: Human papillomavirus type distribution in 30,848 invasive cervical cancers worldwide: Variation by geographical region, histological type and year of publication. Int J Cancer 128: 927-935, 2011.

14. Azuma Y, Kusumoto-Matsuo R, Takeuchi F, Uenoyama A, Kondo K, Tsunoda H, Nagasaka K, Kawana K, Morisada T, Iwata $\mathrm{T}$, et al: Human papillomavirus genotype distribution in cervical intraepithelial neoplasia grade $2 / 3$ and invasive cervical cancer in Japanese women. Jpn J Clin Oncol 44: 910-917, 2014.

15. Chan PK, Ho WC, Chan MC, Wong MC, Yeung AC, Chor JS and Hui M: Meta-analysis on prevalence and attribution of human papillomavirus types 52 and 58 in cervical neoplasia worldwide. PLoS One 9: e107573, 2014.
16. Graham SV: Human Papillomavirus E2 Protein: Linking replication, transcription and RNA processing. J Virol 90: 8384-8388, 2016.

17. Chaiwongkot A, Vinokurova S, Pientong C, Ekalaksananan T, Kongyingyoes B, Kleebkaow P, Chumworathayi B, Patarapadungkit N, Reuschenbach $\mathrm{M}$ and von Knebel Doeberitz M: Differential methylation of E2 binding sites in episomal and integrated HPV 16 genomes in preinvasive and invasive cervical lesions. Int J Cancer 132: 2087-2094, 2013.

18. Alp Ave1 G: Genomic organization and proteins of human papillomavirus. Mikrobiyol Bul 46: 507-515, 2012 (In Turkish).

19. Akagi K, Li J, Broutian TR, Padilla-Nash H, Xiao W, Jiang B, Rocco JW, Teknos TN, Kumar B, Wangsa D, et al: Genome-wide analysis of HPV integration in human cancers reveals recurrent, focal genomic instability. Genome Res 24: 185-199, 2014.

20. Raybould R, Fiander A, Wilkinson GW and Hibbitts S: HPV integration detection in CaSki and $\mathrm{SiHa}$ using detection of integrated papillomavirus sequences and restriction-site PCR. J Virol Methods 206: 51-54, 2014.

21. Klaes R, Woerner SM, Ridder R, Wentzensen N, Duerst M, Schneider A, Lotz B, Melsheimer P and von Knebel Doeberitz M: Dectection of High-Risk cervical intraepithelial neoplasia and cervical cancer by amplification of transcripts derived from integrated papillomavirus oncogenes. Cancer Res 59: 6132-6136, 1999.

22. Karlsen F, Kalantari M, Jenkins A, Pettersen E, Kristensen G, Holm R, Johansson B and Hagmar B: Use of Multiple PCR Sets for Optimal Detection of Human papillomavirus. J Clin Microbiol 34: 2095-2100, 1996.

23. Hillemanns P and Wang XL: Integration of HPV-16 and HPV-18 DNA in vulvar intraepithelial neoplasia. Gynecol Oncol 100: 276-282, 2006.

24. Klimov E, Vinokourova S, Moisjak E, RakhmanalievE, Kobseva V, Laimins L, Kisseljov F and Sulimova G: Human papilloma viruses and cervical tumours: Mapping of integration sites and analysis of adjacent cellular sequences. BMC Cancer 2: 24, 2002.

25. Ok Atılgan A, Tepeoğlu M, Haberal AN, Durukan E, Kuşcu E and Haberal M: Papanicolaou smear findings in solid-organ transplant recipients compared with normal subjects according to the Bethesda 2001 system. Exp Clin Transplant 13 (Suppl 1): S219-S222, 2015.

26. Al-Kadri HM, Kamal M, Bamuhair SS, Omair AA and Bamefleh HS: Prevalence and characteristics of abnormal Papanicolaou smear in Central Saudi Arabia. Saudi Med J 36: 117-122, 2015.

27. Psifidi A, Dovas CI and Banos G: A comparison of six methods for genomic DNA extraction suitable for PCR-based genotypingapplications using ovine milk samples. Mol Cell Probes 24: 93-98, 2010.

28. Psifidi A, Dovas CI, Bramis G, Lazou T, Russel CL, Arsenos G and Banos G: Comparison of eleven methods for genomic DNA extraction suitable for large-scale whole-genome genotyping and long-Term DNA banking using blood samples. PLoS One 10: e0115960, 2015.

29. Kim ST, Chun JW, Park G and Koh JW: Comparative quantification of plasma TDRD7 mRNA in cataract patients by real-time polymerase chain reaction. Korean J Ophthalmol 28: 343-350, 2014.

30. Livak KJ and Schmittgen TD: Analysis of relative gene expression data using real-time quantitative PCR and the 2(-Delta Delta C(T)) method. Methods 25: 402-408, 2001.

31. Yuan B, Li XY, Zhu T, Yuan L, Hu JP, Chen J, Gao W and Ren WZ: Antibody study in canine distemper virus nucleocapsid protein gene-immunized mice. Genet Mol Res 14: 3098-3105, 2015.

32. Das P, Thomas A, Kannan S, Deodhar K, Shrivastava SK, Mahantshetty $U$ and Mulherkar R: Human papillomavirus (HPV) genome status \& cervical cancer outcome-A retrospective study. Indian J Med Res 142: 525-532, 2015.

33. Onyekwuluje JM, Steinau M, Swan DC and Unger ER: A real-time PCR assay for HPV52 detection and viral load quantification. Clin Lab 58: 61-66, 2012.

34. Ardhaoui M, Ennaifer E, Letaief H, Salsabil R, Lassili T, Chahed K, Bougatef S, Bahrini A, El Fehri E, Ouerhani K, et al: Prevalence, genotype distribution and risk factors for cervical human papillomavirus infection in the grand tunis region, Tunisia. PLoS One 11: e0157432, 2016.

35. Salehi-Vaziri M, Sadeghi F, Bokharaei-Salim F, Younesi S, Alinaghi S, Monavari SH and Keyvani H: The prevalence and genotype distribution of human papillomavirus in the genital tract of males in Iran. Jundishapur J Microbiol 8: e21912, 2015. 
36. Ewaisha R, Meshay I, Resnik J, Katchman BA and Anderson KS: Programmable protein arrays for immunoprofiling HPV-associated cancers. Proteomics 16: 1215-1224, 2016.

37. Castle PE, Schiffman M, Scott DR, Sherman ME, Glass AG, Rush BB, Schussler JE, Wacholder S and Lorincz AT: Semiquantitative human papillomavirus type 16 viral load and the prospective risk of cervicalprecancer and cancer. Cancer Epidemiol Biomarkers Prev 14: 1311-1314, 2005.

38. Shukla S, Mahata S, Shishodia G, Pande S, Verma G, Hedau S, Bhambhani S, Kumari A, Batra S, Basir SF, et al: Physical state \& copy number of high risk human papillomavirus type 16 DNA in progression of cervical cancer. Indian J Med Res 139: 531-543, 2014

39. Wentzensen N, Gravitt PE, Long R, Schiffman M, Dunn ST, Carreon JD, Allen RA, Gunja M, Zuna RE, Sherman ME, et al: Human papillomavirus load measured by Linear Array correlates with quantitative PCR in cervical cytology specimens. J Clin Microbiol 50: 1564-1570, 2012.

40. Theelen W, Reijans M, Simons G, Ramaekers FC, Speel EJ and Hopman AH: A new multiparameter assay to assess HPV 16/18, viral load and physical status together with gain of telomerase genes in HPV-related cancers. Int J Cancer 126: 959-975, 2010.

41. Jacobs MV, Walboomers JM, van Beek J, Voorhorst FJ Verheijen RH, Meijer CJ, van den Brule AJ, Helmerhorst TJ and Snijders PJ: A quantitative polymerase chain reaction-enzyme immunoassay for accurate measurements of human papillomavirus type 16 DNA levels in cervical scrapings. Br J Cancer 81: 114-121, 1999.
42. Constandinou-Williams C, Collins SI, Roberts S, Young LS, Woodman CB and Murray PG: Is human papillomavirus viral load a clinically useful predictive marker? A longitudinal study. Cancer Epidemiol Biomarkers Prev 19: 832-837, 2010.

43. Zhang R, He YF, Chen M, Chen CM, Zhu QJ, Lu H, Wei ZH, Li F, Zhang XX, Xu CJ and Yu L: Diagnosis of 25 genotypes of human papillomaviruses for their physical statuses in cervical precancerous/cancerous lesions: a comparison of E2/E6E7 ratio-based vs. Multiple E1-L1/E6E7 ratio-based detection techniques. J Transl Med 12: 282, 2014.

44. Kadaja M, Sumerina A, Verst T, Ojarand M, Ustav E and Ustav M: Genomic instability of the host cell induced by the human papillomavirus replication machinery. EMBO J 26: 2180-2191, 2007.

45. Johansson C, Somberg M, Li X, Backström Winquist E, Fay J, Ryan F, Pim D, Banks L and Schwartz S: HPV-16 E2 contributes to induction of HPV-16 late gene expression by inhibiting early polyadenylation. EMBO J 31: 3212-3227, 2012.

46. Al-Shabanah OA, Hafez MM, Hassan ZK, Sayed-Ahmed MM, Abozeed WN, Al-Rejaie SS and Alsheikh AA: Human papillomavirus genotyping and integration in ovarian cancer Saudi patients. Virol J 10: 343, 2013.

47. Das P, Thomas A, Mahantshetty U, Shrivastava SK, Deodhar K and Mulherkar R: HPV genotyping and site of viral integration in cervical cancers in Indian women. PLoS One 7: e41012, 2012. 